\title{
EFEITOS DA FARINHA DE FOLHAS DE MANDIOCA SOBRE A PEROXIDAÇÃO LIPÍDICA, O PERFIL LIPÍDICO SANGÜÍNEO E O PESO DO FÍGADO DE RATOS ${ }^{1}$
}

\author{
Effects of cassava leaf flour on lipidic peroxidation, blood lipidic profile and liver weight of rats
}

\author{
Daniela Séfora de Melo ${ }^{2}$, Angelita Duarte Corrêa ${ }^{3}$, Flávia Cristina Almeida Marcos ${ }^{4}$, \\ Raimundo Vicente de Sousa ${ }^{5}$, Celeste Maria Patto de Abreu ${ }^{3}$, Custódio Donizete dos Santos ${ }^{3}$
}

\begin{abstract}
RESUMO
Sabe-se que polifenóis e saponinas apresentam efeitos antioxidante e hipolipidêmico, respectivamente. Como folhas de mandioca contêm estas substâncias, foi investigado o efeito de dietas contendo a farinha de folhas de mandioca (FFM) sobre a peroxidação lipídica, o perfil lipídico sangüíneo e o peso do fígado de ratos. Para isto, folhas maduras de mandioca (Manihot esculenta Crantz cv. Cacao) foram secas em estufa ventilada a $30-35^{\circ} \mathrm{C}$ e trituradas sem os pecíolos. Um ensaio biológico, com 32 ratos machos Wistar, foi conduzido por um período de 7 semanas com quatro tratamentos: dieta controle e dietas contendo 5\%, 10\% e $15 \%$ de FFM, sendo todas suplementadas com $1 \%$ de colesterol. As dietas se apresentaram isoenergéticas e contendo os mesmos níveis de proteína digestível e fibras. Foi observado que dietas contendo FFM não apresentaram efeitos significativos sobre o perfil lipídico sangüíneo e sobre as variáveis de desempenho, mas contribuiram para o aumento no peso do fígado. Já as dietas contendo $10 \%$ e $15 \%$ de FFM foram associadas à redução nos teores plasmáticos de substâncias reativas ao ácido tiobarbitúrico.
\end{abstract}

Termos para indexação: Folhas de mandioca, lignina, saponina, polifenóis, cianeto, ratos Wistar.

\begin{abstract}
It is well known that polyphenols and saponins present antioxidant and hypolipidemic effects, respectively. As cassava leaves contains these substances, the effects of diets supplemented with cassava leaf flour (CLF) on lipidic peroxidation, blood lipid profile and liver weight of rats were investigated. Therefore, ripe cassava leaves (Manihot esculenta Crantz cv. Cacao) were dried in a ventilated oven at $30-35{ }^{\circ} \mathrm{C}$ and ground without the petioles. A biological assay was conducted during 7 weeks with 32 Wistar male rats submitted to four treatments: control diet and diets containing 5\%,10\% and 15\% CLF, all supplemented with $1 \%$ cholesterol. Diets were isoenergetic and contained the same levels of digestible protein, and fibers. It was observed that diets containing CLF presented no significant effect on blood lipidic profile or performance variables, but contributed to an increase in liver weight. Diets containing $10 \%$ and $15 \%$ CLF were associated with a reduction in plasmatic levels of thiobarbituric acid reactive substances.
\end{abstract}

Index terms: Cassava leaves, lignin, saponin, polyphenols, cyanide, Wistar rats.

\section{(Recebido em 3 de março de 2005 e aprovado em 20 de outubro de 2005)}

\section{INTRODUÇÃO}

Segundo Monteiro (1992), no Brasil, a prevalência da desnutrição crônica atinge $15,4 \%$ das crianças menores de cinco anos e a distribuição regional da desnutrição não é homogênea, sendo significativamente maior nos estados do Norte urbano e Nordeste. Devido a estes elevados índices de desnutrição, várias organizações governamentais e não governamentais, como a Fundação Nacional de Saúde e Pastoral da Criança têm apresentado como alternativa o uso da "multimistura" como suplemento alimentar.

Um dos ingredientes desta "multimistura" é a farinha de folhas de mandioca (FFM) e o seu uso deve-se ao seu conteúdo protéico, vitaminas e minerais. Todavia, as folhas de mandioca apresentam algumas substâncias consideradas antinutritivas como, cianeto, polifenóis (taninos), nitrato, ácido oxálico, hemaglutinina, saponinas e inibidores de tripsina (CORRÊA, 2000; CORRÊA et al., 2004; WOBETO, 2003). Estas substâncias podem ocasionar efeitos tóxicos, dependendo da quantidade consumida ou, então, podem trazer benefícios, dependendo da substância e ou da circunstância.

Muitos estudos têm sido realizados com folhas de mandioca objetivando propiciar níveis baixos destas substâncias antinutritivas. Já se sabe que a forma de secagem das folhas, a idade da planta e a própria cultivar têm grande influência tanto sobre os teores de nutrientes quanto no de antinutrientes (CORRÊA, 2000; CORRÊA et al., 2004; WOBETO, 2003).

\footnotetext{
${ }^{1}$ Parte da dissertação do primeiro autor.

${ }^{2}$ Mestre em Agroquímica e Agrobioquímica - Rua Capelinha, 871, apto 201 - Bairro São Judas - 35.501-244 - Divinópolis, MG

${ }^{3}$ Professores do Departamento de Química/DQI - Universidade Federal de Lavras/UFLA - Cx. P. 3037 - 37200-000 - Lavras, MG - angelita@ufla.br; celeste@ufla.br; santosc@ufla.br

${ }^{4}$ Aluna de iniciação científica do Departamento de Química/DQI - Universidade Federal de Lavras/UFLA - Cx. P. 3037 - $37200-000$ - Lavras, MG FAPEMIG - uflavia@pop.com.br

${ }^{5}$ Professor do Departamento de Medicina Veterinária/DMV -Universidade Federal de Lavras/UFLA - Cx. P. 3037-37200-000-Lavras, MG - rvsousa@ufla.br
} 
Os polifenóis (taninos) são considerados antinutrientes porque diminuem a digestibilidade protéica. Entretanto, vários estudos relataram a atividade antioxidante destes compostos (CAI et al., 2002; OROZCO et al., 2003) que podem estar relacionados com a prevenção de doenças cardiovasculares, pois aumentam a resistência da LDL (lipoproteína de baixa densidade) à oxidação e, indiretamente, reduzem a depleção de vitaminas antioxidantes (MIURA et al., 2000). Já as saponinas, por serem capazes de formar complexos com esteróides e fosfolipídeos das membranas das células da mucosa intestinal, apresentam propriedades irritantes. No entanto, outros estudos mostram seu efeito hipolipidêmico, por ligarem-se aos ácidos biliares e ou colesterol, impedindo sua absorção (RAO \& KENDALL, 1986).

Estudos avaliando a qualidade da proteína e, a biodisponibilidade dos minerais e vitaminas, também já foram realizados (HEINEMANN et al., 1998; NWOKOLO, 1987; ORTEGA-FLORES et al., 2003a; ROGERS \& MILNER, 1963). No entanto, pesquisas que avaliem o efeito de substâncias presentes nas folhas de mandioca, como polifenóis e saponinas, não constam na literatura pesquisada.

Portanto, neste trabalho estudou-se o efeito da adição de $5 \%, 10 \%$ e $15 \%$ de FFM em dietas hipercolesterolêmicas, sobre a peroxidação lipídica, o perfil lipídico sanguiíneo e o peso do fígado de ratos. A adoção de uma dieta hipercolesterolêmica é para melhor evidenciar uma possível redução de colesterol, acarretada por determinadas substâncias contidas nas folhas de mandioca.

\section{MATERIAL E MÉTODOS}

\section{Farinha de folhas de mandioca (FFM)}

\section{Preparo da FFM}

Folhas maduras de mandioca (Manihot esculenta Crantz cv. Cacao) foram colhidas aleatoriamente aos 12 meses de idade da planta, no mês de dezembro de 2003 e transportadas para o Laboratório de Bioquímica do Departamento de Química da Universidade Federal de Lavras. As folhas foram lavadas em água corrente e água destilada e em seguida secas em estufa ventilada à temperatura de $30-35{ }^{\circ} \mathrm{C}$ por 48 horas e em seguida trituradas em moinho. A FFM foi armazenada em recipiente de plástico e estocada em geladeira, até as análises e uso nas dietas experimentais. As análises foram realizadas em triplicatas.

\section{Composição centesimal}

A umidade, extrato etéreo, proteína bruta (utilizando-se o fator de conversão 6,25) e cinza, na FFM e nas dietas experimentais, foram determinados segundo AOAC (1995). A fibra detergente neutro e lignina foram quantificadas pelo método proposto por Van Soest, citado por Silva (1990). O extrato não nitrogenado (ENN) foi calculado por diferença.

Saponina

A saponina da FFM foi extraída com etanol sob agitação, à temperatura ambiente. $\mathrm{O}$ teor de saponina foi determinado pela reação da saponina com o anisaldeído, em meio ácido, produzindo um composto com $\lambda$ max $a 430$ nm (BACCOU et al., 1977).

\section{Polifenóis}

A extração de polifenóis da FFM foi realizada com metanol $50 \%$, em refluxo por três vezes consecutivas, a $80^{\circ} \mathrm{C}$ e os extratos reunidos e submetidos à dosagem de polifenóis utilizando-se o reagente de Folin-Denis, o qual é reduzido pelos fenóis a um complexo de coloração azul em solução alcalina, que é medido a $760 \mathrm{~nm}$ (GOLDSTEIN \& SWAIN, 1963).

\section{Cianeto}

A extração dos glicosídeos cianogênicos da FFM foi feita utilizando-se solução ácida e a concentração de cianeto medida após ação enzimática da linamarase obtida das folhas de mandioca, conforme metodologia descrita por Corrêa et al. (2002). O cianeto de potássio foi usado como padrão.

\section{Digestibilidade protéica in vitro}

A FFM com teor de nitrogênio conhecido foi agitada com uma solução ácida de pepsina por 3 horas e, após neutralização foi adicionada a solução de pancreatina, deixando-se em agitação por 21 horas. Ao finalizar a digestão, ácido tricloroacético a $10 \%$ foi adicionado para encerrar a ação enzimática e precipitar as proteínas não digeridas. Após centrifugação, dosou-se o nitrogênio no sobrenadante (AKESON \& STAHMANN, 1964). A caseína foi usada como controle e os resultados expressos em porcentagem.

\section{Ensaio biológico}

Foram utilizados 32 ratos, machos albinos (Rattus novergicus), da linhagem Wistar, provenientes do Biotério do Departamento de Medicina Veterinária da Universidade Federal de Lavras, em fase de crescimento e com peso 
médio inicial de 129,08 $\pm 22,26$ g. Após os animais terem sido desmamados, aos 21 dias, eles permaneceram com dieta padrão (Tabela 1) por 2 semanas e, então, iniciou-se o ensaio. Os animais foram mantidos em gaiolas individuais, em sala com temperatura de $25 \pm 3{ }^{\circ} \mathrm{C}$ (ciclo dia:noite 12 horas) e com acesso a ração e água ad libitum, por um período de 49 dias.

Os animais foram pesados e distribuídos aleatoriamente em 4 grupos, com oito animais por grupo, constituindo os tratamentos: controle - dieta padrão e três outros grupos com dietas contendo $5 \%, 10 \%$ e $15 \%$ de FFM. Em todos os grupos as dietas continham $1 \%$ de colesterol, mostrando-se isocalóricas e contendo o mesmo teor de fibra e proteína digestível. As dietas experimentais (Tabela 2) foram preparadas de acordo com AIN-93G (REEVES et al., 1993).

Durante todo o experimento, realizou-se semanalmente, o controle do peso corporal e do consumo da ração dos animais para o cálculo do coeficiente de eficiência alimentar e elaboração da curva de crescimento.

TABELA 1 - Dieta padrão ministrada aos ratos após terem sido desmamados.

\begin{tabular}{lc}
\hline Constituintes & Dieta $^{1}$ \\
\hline Umidade & $12,5 \mathrm{~g} / 100 \mathrm{~g}$ \\
Extrato etéreo & $4 \mathrm{~g} / 100 \mathrm{~g}$ \\
Proteína bruta & $22 \mathrm{~g} / 100 \mathrm{~g}$ \\
Minerais & $10 \mathrm{~g} / 100 \mathrm{~g}$ \\
Fibras & $8 \mathrm{~g} / 100 \mathrm{~g}$ \\
Cálcio & $1,4 \mathrm{~g} / 100 \mathrm{~g}$ \\
Fósforo & $0,8 \mathrm{~g} / 100 \mathrm{~g}$ \\
Metionina & $300 \mathrm{mg} / 100 \mathrm{~g}$ \\
Lisina & $100 \mathrm{mg} / 100 \mathrm{~g}$ \\
\hline
\end{tabular}

${ }^{1}$ Baseado em recomendações do National Research Council e National Institute of Health -USA. Rótulo registrado no Ministério da Agricultura e Reforma Agrária sob número PR 58033-00103.

Ao término do experimento, os animais foram deixados em jejum, por cerca de 12 horas e, em seguida, foram anestesiados com éter etílico por inalação em câmara fechada. O sangue foi retirado dos grandes vasos abdominais e, em seguida centrifugado para obtenção do soro, que foi analisado quanto ao colesterol total, triacilgliceróis, colesterol na fração HDL, colesterol nas frações LDL + VLDL e substâncias reativas ao ácido tiobarbitúrico (TBARS), segundo técnica do Instituto Adolf Lutz (1985).

O fígado foi retirado por meio de laparotomia mediana, lavado em solução salina $0,9 \%$, secado, pesado, e estocado a $-25^{\circ} \mathrm{C}$ para posteriores análises.

Análise estatística

O delineamento estatístico foi inteiramente casualizado, com quatro tratamentos e oito repetições, representando cada animal uma parcela experimental. Procedeu-se à análise de variância para a determinação do valor de ' $F$ '. Para ' $F$ ' significativo, utilizou-se o teste de Scott-Knott a 5\% de probabilidade para a comparação entre as médias.

\section{RESULTADOS E DISCUSSÃO}

\section{Farinha de folhas de mandioca}

Na Tabela 3 são apresentados os resultados da composição centesimal da farinha de folhas de mandioca (FFM).

O teor de proteína bruta, extrato etéreo e cinza da FFM analisada estão dentro da faixa de variação relatada em outros trabalhos, para as folhas de outras cultivares de mandioca (CARVALHO et al., 1986; CORRÊA et al., 2004; MADRUGA \& CÂMARA, 2000; ORTEGA-FLORES et al., 2003b; WOBETO, 2003).

Reed et al. (1982), avaliando a composição química de folhas de mandioca, encontraram teores para FDN $(35,40$ $\mathrm{g} / 100 \mathrm{~g}$ MS) e lignina (7,20 g/100 g MS) diferentes dos encontrados neste trabalho. No entanto, Corrêa (2000) encontrou valores de FDN (32,82 g/100 g MS) próximos aos deste trabalho. Essas diferenças encontradas, provavelmente, são inerentes à cultivar e devido à idade da planta e à maturidade das folhas.

Na Tabela 4 são mostrados os teores de saponina, polifenóis, cianeto e digestibilidade protéica in vitro da FFM.

Wobeto (2003) encontrou níveis de saponina na FFM, independente da cultivar e aos 12 meses de idade da planta, variando de 1,74 a 4,41 g/100 g MS. O método utilizado para ambos os trabalhos foi o mesmo, desta forma, a diferença observada, provavelmente, é devido à cultivar analisada, dentre outros fatores.

Os teores de polifenóis e a digestibilidade protéica in vitro da FFM estão dentro da faixa de variação encontrada na literatura para diferentes cultivares e processamentos (CORREAA et al., 2004; FONSECA, 1996; PADMAJA, 1989; WOBETO, 2003). 
TABELA 2 - Composição das dietas experimentais (g/100 g).

\begin{tabular}{lcccc}
\hline & \multicolumn{3}{c}{ Grupos } \\
\cline { 2 - 5 } Ingredientes & Controle & $\mathbf{5 \%}$ FFM & $\mathbf{1 0 \%}$ FFM & $\mathbf{1 5 \%}$ FFM \\
\hline Amido & 40 & 40 & 40 & 40 \\
Caseína & 20 & 19,5 & 19 & 18,5 \\
Sacarose & 10 & 10 & 10 & 10 \\
Óleo & 10 & 10 & 10 & 10 \\
Celulose & 5 & 3,5 & 2 & 0,5 \\
Mistura mineral & 3,5 & 3,5 & 3,5 & 3,5 \\
Mistura vitamínica & 1 & 1 & 1 & 1 \\
Metionina & 0,5 & 0,5 & 0,5 & 0,5 \\
Colesterol & 1 & 1 & 1 & 1 \\
Caolim & 9 & 6 & 3 & 10 \\
FFM & 0 & 5 & 10 & 100 \\
\hline Total & 100 & 100 & 358,44 & 358,64 \\
kcal/100g & 358,00 & 358,24 & 4,65 & 4,47 \\
\hline Fibra & 5,00 & 4,83 & 15,11 & 15,16 \\
Proteína digestível & 2 & 15,05 & 17,23 & 18,35 \\
Proteína bruta & 15,00 & 16,11 & & \\
\hline
\end{tabular}

${ }^{1}$ Contendo $75 \%$ de proteína bruta.

${ }^{2}$ Os teores de fibra (FDN - 26,50 g/100 g) e proteína digestível (proteína bruta - 29,86 g/100 g e digestibilidade protéica - 28,88\%) encontrados na FFM foram descontados nos teores de celulose e caseína, respectivamente, para cada dieta.

TABELA 3 - Composição centesimal da farinha de folhas de mandioca (FFM).

\begin{tabular}{lc}
\hline Constituintes & FFM $^{\mathbf{1}}(\mathbf{g} / \mathbf{1 0 0 g})$ \\
\hline Umidade $^{2}$ & $8,31 \pm 0,04$ \\
Extrato etéreo & $9,20 \pm 0,03$ \\
Proteína bruta & $29,86 \pm 0,10$ \\
Fibra $\left(\mathrm{FDN}^{3}\right)$ & $26,50 \pm 2,61$ \\
Lignina & $16,80 \pm 0,40$ \\
Cinza & $6,15 \pm 0,52$ \\
ENN $^{4}$ & $19,98 \pm 2,74$
\end{tabular}

${ }^{1}$ Média de três determinações \pm desvio padrão.

${ }^{2}$ Umidade das folhas frescas de mandioca: $67,93 \pm 0,06 \mathrm{~g} / 100 \mathrm{~g}$

${ }^{3}$ FDN - fibra detergente neutro.

${ }^{4}$ ENN - extrato não nitrogenado.

O teor de cianeto na FFM foi superior aos encontrados por Corrêa (2000), cultivar Baiana, para folhas secas em estufa a $30{ }^{\circ} \mathrm{C}$ e $40{ }^{\circ} \mathrm{C}$ e aos encontrados por Wobeto (2003), para diferentes cultivares e idades da planta e folhas secas à sombra. No entanto, Ravindran \& Ravindran (1988) encontraram para folhas maduras secas ao sol e em seguida em estufa a $60^{\circ} \mathrm{C}$ por 24 horas, valores superiores. Estas variações devem-se, provavelmente, às diferenças genética entre cultivares, às idades da planta, à fertilidade do solo, e às formas de secagem das folhas.

A dose letal $\left(\mathrm{DL}_{50}\right)$ de cianeto por via oral varia de 0,5 a $3 \mathrm{mg} / \mathrm{kg}$ de peso corporal (WOGAN \& MARLETTA, 1993). Assim para o cianeto encontrado na FFM estudada, a ingestão de $15 \mathrm{~g}$ de farinha para um indivíduo de $70 \mathrm{~kg}$, que corresponde a $0,26 \mathrm{mg}$ de cianeto/ $\mathrm{kg}$ de peso corporal, ou como vem sendo usada na formulação de novos produtos na proporção de $3 \%$, poderia ser considerada segura. Porém, é necessário ressaltar a toxicidade crônica atribuída ao consumo de doses menores de cianeto em um intervalo de tempo maior.

TABELA 4 - Fatores antinutricionais e digestibilidade protéica in vitro da farinha de folhas de mandioca (FFM).

\begin{tabular}{ll}
\hline Constituintes & \multicolumn{1}{c}{ FFM $^{\mathbf{1}}$} \\
\hline Saponina & $1,07 \pm 0,09(\mathrm{~g} / 100 \mathrm{~g}$ MS $)$ \\
Polifenóis & $4,72 \pm 0,64(\mathrm{~g} / 100 \mathrm{~g}$ MS $)$ \\
Cianeto & $123,64 \pm 13,42(\mathrm{mg} / 100 \mathrm{~g} \mathrm{MS})$ \\
Digestibilidade protéica & $28,88 \pm 0,18(\%)$ \\
in vitro & \\
\hline
\end{tabular}

${ }^{1}$ Média de três determinações \pm desvio padrão. 


\section{Ensaio biológico}

Dietas e variáveis de desempenho

A adição da quantidade máxima de 15\% FFM usada nas dietas experimentais foi baseada no estudo feito por Ortega-Flores et al. (2003b), que utilizaram a FFM como fonte protéica. Eles empregaram três níveis de FFM: 12,5 $\mathrm{g}, 25 \mathrm{~g}$ e $50 \mathrm{~g}$ por $100 \mathrm{~g}$ da dieta. Os resultados mostraram que apenas a dieta com 12,5 g de FFM não apresentou redução significativa, quando comparada ao grupo controle, do coeficiente de eficiência alimentar (CEA), ganho de peso médio diário (GMD) e consumo médio diário (CMD). Portanto valores próximos a 12,5 g de FFM por 100 $\mathrm{g}$ da dieta não trariam prejuízos para o desenvolvimento dos animais.

As dietas oferecidas aos animais em fase experimental foram submetidas à análise de composição centesimal, a qual segue apresentada na Tabela 5. Observa-se que os teores de proteína bruta aumentaram da dieta controle para as dietas contendo 5\%, 10\% e 15\% de FFM, pois levaramse em conta o teor em proteína bruta e a digestibilidade protéica in vitro da FFM na elaboração das mesmas. O teor de FDN da FFM também foi considerado e, portanto grupos com quantidades crescentes de FFM apresentaram praticamente a mesma concentração de FDN.

O CEA do grupo com dieta controle $(0,187)$ não diferiu estatisticamente dos grupos com dietas contendo $5 \%(0,198), 10 \%(0,198)$ e $15 \%(0,204)$ de FFM. Estes dados estão de acordo com os obtidos por Ortega-Flores et al. (2003b) e Ross \& Enriquez (1969), conforme esperado.
Na Figura 1 está representada a curva de crescimento dos ratos tratados por 7 semanas com dieta controle e contendo 5\%, 10\% e 15\% de FFM. A análise de variância para os pesos dos animais no decorrer da fase experimental (curva de crescimento) mostrou diferença significativa, a $1 \%$ de probabilidade, pelo teste $\mathrm{F}$ apenas para o tempo.

Observa-se que, ao final do experimento, os animais alcançaram aproximadamente $50 \%$ do peso adulto. A variação do ganho de peso com o passar do tempo começa a reduzir até o rato alcançar a fase adulta.

Colesterol total, suas frações e substâncias reativas ao ácido tiobarbitúrico

Eufrásio (2003) e Silva (2002) encontraram elevação significativa do colesterol total (CT) no sangue de ratos alimentados com dietas contendo $1 \%$ de colesterol, quando comparado com o grupo controle, sem colesterol. Portanto, para proporcionar hipercolesterolemia nos ratos, adicionou-se $1 \%$ de colesterol às dietas deste experimento.

Na Tabela 6 são apresentados os teores médios das frações lipídicas e teores de substâncias reativas ao ácido tiobarbitúrico no sangue dos ratos experimentais. As análises de variância dos teores de CT, colesterol na fração HDL (HDL-c), colesterol nas frações VLDL + LDL (VLDL-c + LDLc) e relação HDL-c/CT no sangue, ao final do experimento, não mostraram diferenças significativas, pelo teste $\mathrm{F}$.

Apesar do grupo controle ter apresentado as menores médias para CT, VLDL-c+LDL-c e as maiores para HDL-c e relação HDL-c/CT, elas não foram estatisticamente diferentes das dietas com FFM.

TABELA 5 - Composição centesimal das dietas experimentais em g/100 g1 .

\begin{tabular}{lcccc}
\hline & \multicolumn{3}{c}{ Dietas } \\
\cline { 2 - 5 } Constituintes & Controle & $\mathbf{5 \%}$ FFM & $\mathbf{1 0 \%}$ FFM & $\mathbf{1 5 \%}$ FFM \\
\hline Umidade & $9,22 \pm 0,05$ & $8,08 \pm 0,28$ & $9,12 \pm 0,06$ & $9,31 \pm 0,10$ \\
Extrato etéreo & $10,36 \pm 0,28$ & $11,74 \pm 0,84$ & $10,95 \pm 0,60$ & $10,52 \pm 0,68$ \\
Proteína bruta & $14,71 \pm 0,67$ & $16,79 \pm 0,52$ & $18,67 \pm 0,19$ & $19,81 \pm 0,35$ \\
Cinza & $10,67 \pm 0,42$ & $8,50 \pm 0,14$ & $6,18 \pm 0,26$ & $3,21 \pm 0,16$ \\
FDN $^{2}$ & $5,89 \pm 0,21$ & $5,52 \pm 0,37$ & $5,97 \pm 0,46$ & $5,23 \pm 0,13$ \\
ENN $^{3}$ & $49,36 \pm 0,38$ & $49,09 \pm 1,82$ & $49,70 \pm 1,11$ & $51,89 \pm 1,01$ \\
\hline
\end{tabular}

${ }^{1}$ Média de três determinações \pm desvio padrão.

${ }^{2} \mathrm{FDN}$ - fibra detergente neutro.

${ }^{3} \mathrm{ENN}$ - extrato não nitrogenado. 


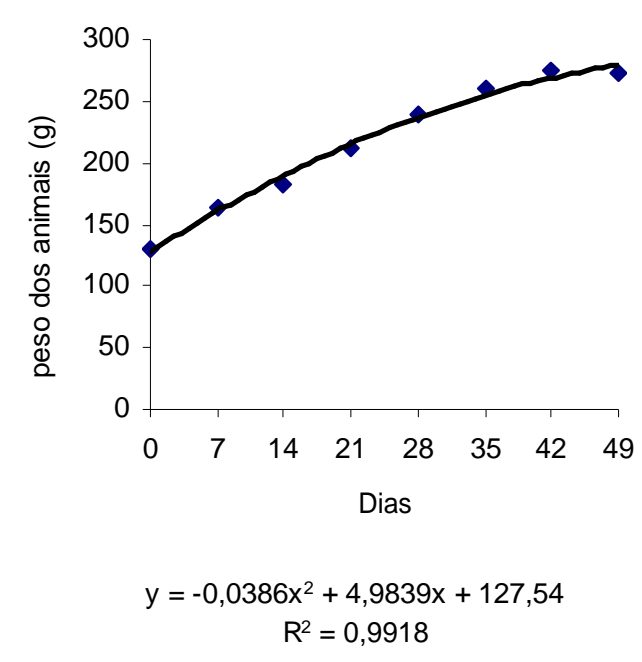

FIGURA 1 - Curva de crescimento dos ratos com as dietas durante a fase experimental.

Considerando-se o teor de lignina da FFM $(15,40$ $\mathrm{g} / 100 \mathrm{~g}$ ), as dietas com $15 \%, 10 \%$ e $5 \%$ de FFM apresentaram 2,31; 1,54 e 0,77 g de lignina/100 g de dieta, respectivamente. Valencia \& Chavez (1997), investigando o efeito da suplementação de $1,25 \%$ de lignina, por um período de 4 semanas, observaram que os níveis de TAG no plasma foram significativamente reduzidos no grupo controle e no grupo com alta ingestão de colesterol. No entanto, neste trabalho não foi observado tal efeito, provavelmente, devido ao tipo de lignina das folhas de mandioca. Quanto maior a hidrofobicidade da molécula de lignina maior é sua capacidade para formar complexos com colesterol e ou ácidos biliares. Ou talvez, porque a lignina da FFM por estar contida na matriz do alimento foi impedida de exercer sua ação.

Zdunczyk et al. (2002), avaliando a atividade biológica de extratos de polifenóis de diferentes fontes, como catequinas de chá verde e taninos condensados de feijão faba, adicionados à dieta na proporção de $0,8 \mathrm{~g}$ de polifenóis/100 g de dieta, verificaram que apenas o extrato de catequina diminuiu o CT e a LDL-c no sangue. Sabe-se que folhas de mandioca são ricas em polifenóis e especialmente taninos condensados. Considerando-se a quantidade de polifenóis na FFM, 4,33 g/100 g, as dietas com $15 \%, 10 \%$ e $5 \%$ de FFM apresentaram 0,66; 0,44 e 0,22 $\mathrm{g}$ de polifenóis/100 g de dieta, respectivamente. Parece que esses teores de polifenóis, além de menores em relação ao estudo citado e sendo principalmente taninos, não foram suficientes para reduzir os teores de CT e a LDL-c + VLDLc no sangue dos animais experimentais.

Rao \& Kendall (1986), avaliando o efeito da saponina (Quillaja saponaria Molina) demonstraram que um teor de $0,75 \%$ adicionado à dieta, em ratos, reduziu significativamente a concentração de TAG e CT no soro, comparados com o controle (sem colesterol), após 24 semanas. Considerando a quantidade de saponinas na FFM, as dietas com 15\%, 10\% e 5\% de FFM continham 0,147, 0,098 e 0,049 g/100 g, respectivamente, quantidades relativamente inferiores. Os mesmos autores relataram que um período de 8 semanas não foi suficiente para reduzir os lipídeos sangüíneos. Jenkins \& Atwall (1994), analisando o efeito de diferentes tipos de saponinas, sarsaponin, gypsophila e quillaja, na proporção $0,1 \%, 0,3 \%$ e $0,9 \%$, em pintos, por 28 dias, sobre as concentrações de

TABELA 6 - Teores médios de parâmetros lipídicos (mg/dL) e de TBARS (nmol/mL) no sangue dos ratos após 7 semanas com as dietas experimentais.

\begin{tabular}{lllllll}
\hline Dietas $^{1}$ & CT & TAG & HDL-c & HDL-c/CT & $\begin{array}{l}\text { VLDL-c } \\
\text { +LDL-c }\end{array}$ & TBARS $^{\mathbf{2}}$ \\
\hline Controle & 77,65 & 23,70 & 49,03 & 0,613 & 31,60 & $0,98 \mathrm{a}$ \\
$5 \%$ FFM & 91,32 & 26,02 & 45,34 & 0,528 & 46,39 & $0,93 \mathrm{a}$ \\
$10 \%$ FFM & 83,84 & 23,58 & 45,82 & 0,559 & 38,61 & $0,75 \mathrm{~b}$ \\
$15 \%$ FFM & 85,17 & 29,73 & 42,40 & 0,489 & 44,50 & $0,55 \mathrm{~b}$ \\
\hline
\end{tabular}

${ }^{1}$ Controle - dieta padrão e dietas contendo 5\%, 10\% e 15\% de FFM, todas com 1\% de colesterol.

${ }^{2}$ Letras diferentes na coluna indicam que as médias diferem entre si pelo teste Scott-Knott $(\mathrm{p} \leq 0,05)$.

$\mathrm{CT}$ - colesterol total.

TAG - triacilglicerol.

HDL-c - colesterol na fração HDL.

VLDL-c + LDL-c-colesterol nas frações VLDL e LDL. 
CT e HDL-c, também não encontraram diferenças significativas entre os tratamentos. Assim, além dos menores níveis de saponinas ingeridos pelos animais, um período de 7 semanas provavelmente não foram suficientes para reduzir os lipídeos sangüíneos.

$\mathrm{O}$ uso de plantas medicinais com atividade antioxidante está diretamente relacionado ao conteúdo de taninos e flavonóides e conseqüentemente à sua atividade de seqüestrar radicais livres (FENGLLIN et al., 2004). Como a FFM analisada apresentou uma quantidade considerável de polifenóis $(4,33 \mathrm{~g} / 100 \mathrm{~g})$, ao final do experimento, analisaram-se os teores de substâncias reativas ao ácido tiobarbitúrico (TBARS) no sangue como marcador da peroxidação lipídica.

O grupo controle apresentou o teor médio de TBARS de $0,98 \mathrm{nmol} / \mathrm{mL}$, e os grupos com $5 \%, 10 \%$ e $15 \%$ de FFM, 0,93 nmol/mL; 0,75 nmol/mL; 0,56 nmol/mL, respectivamente (Tabela 6). A análise de variância para estes dados mostrou diferença significativa a $1 \%$ para o teste F. Os grupos contendo $10 \%$ e $15 \%$ de FFM não foram estatisticamente diferentes entre si, porém, foram menores $(\mathrm{p} \leq 0,05)$ que os outros dois grupos. Constatou-se que as dietas contendo acima de $10 \%$ de FFM inibiram a formação de dialdeído malônico, mostrando que houve ação antioxidante dos compostos presentes nesta farinha.

A relação média, peso seco do fígado/peso corporal, para os animais do grupo controle e contendo 5\%, $10 \% \mathrm{e}$ 15\% de FFM foram: 1,067; 1,517; 1,592 e 1,419, respectivamente. $\mathrm{O}$ grupo controle apresentou a menor relação $(\mathrm{p} \leq 0,05)$. Os grupos contendo FFM não diferiram entre si.

Machado et al. (2003), estudando o efeito de probiótico no peso do fígado de ratos alimentados com dieta contendo $1 \%$ colesterol e $0,1 \%$ de ácido cólico observaram indução de fígado gorduroso nos animais, com aumento de peso e alteração de sua coloração normal. Neste trabalho a cor do fígado não foi analisada, mas a maior relação peso seco do fígado/ peso corporal sugere o acúmulo de gordura no fígado.

Sousa et al. (2002) estudaram o efeito da exposição prolongada (15 dias) de cianeto de potássio em ratos nas doses 0,$12 ; 0,36 ; 1,20$ e 3,60 mg de $\mathrm{CN}^{-} / \mathrm{kg}$ de peso corporal/ dia, adicionado a água. Uma redução significativa no ganho de peso foi encontrada para o grupo exposto à 3,60 mg de $\mathrm{CN}^{-} / \mathrm{kg}$ de peso corporal/dia quando comparado ao controle. Considerando-se o teor de cianeto quantificado na FFM $(113,37 \mathrm{mg} / 100 \mathrm{~g})$ e ainda que cada animal ingeriu em média $15 \mathrm{~g}$ de dieta/dia e pesou em média $216 \mathrm{~g}$, eles estariam ingerindo aproximadamente 3,93; 7,86 e 11,79 mg de $\mathrm{CN}^{-} / \mathrm{kg}$ de peso corporal/dia. Possivelmente, o cianeto da FFM apresentou o mesmo efeito hepatotóxico sem, contudo interferir no ganho de peso dos animais.

Witthawaskul et al. (2003) estudaram a toxicidade subaguda de saponinas isoladas de Schefflera leucantha Vinguier em ratos, em uma dose oral de $1.000 \mathrm{mg} / \mathrm{kg}$ de peso corporal/dia, por um período de 14 dias. Os resultados mostraram aumento no peso do fígado no grupo tratado com saponina quando comparado ao grupo controle. Os autores concluíram que as saponinas têm um impacto direto sobre as funções do fígado e que uma avaliação adicional de toxicidade crônica é recomendada. Considerando a quantidade de saponinas na FFM, $980 \mathrm{mg} / 100 \mathrm{~g}$, as dietas com 5\%, 10\% e 15\% FFM continham, 49, 98 e $147 \mathrm{mg}$ de saponina/100g, respectivamente. Se cada rato ingeriu aproximadamente $15 \mathrm{~g}$ da dieta/dia e pesava, em média, 216 $\mathrm{g}$, a dose de saponinas ingerida foi 34,03; 68,06 e 102,08 $\mathrm{mg} / \mathrm{kg}$ de peso corporal/dia, respectivamente. Quando comparam-se as saponinas da dieta com 15\% de FFM com a quantidade de saponinas ingerida no trabalho citado, constatou-se que aquelas são cerca de 10 vezes menores. Como houve uma grande diferença no tempo de duração dos experimentos, 14 e 49 dias, sugere-se que uma das causas para o aumento no peso do fígado nos grupos alimentados com FFM pode ser devido à saponina, cujas diferenças nas quantidades foi compensada pelo maior tempo de exposição à substância.

As saponinas presentes na FFM não tiveram efeito sobre o perfil lipídico sangüíneo, provavelmente pela menor quantidade ingerida pelos animais e menor tempo experimental, comparados a outros estudos. No entanto, um maior período experimental poderia reduzir CT e TAG sangüíneos, mas também levaria a um déficit da função hepática, ocasionado pelo maior peso e conseqüente acúmulo desses lipídeos no fígado.

\section{CONCLUSÕES}

Dietas isocalóricas contendo até $15 \%$ de farinha de folhas de mandioca e $1 \%$ de colesterol, cuja proteína digestível e fibras foram corrigidas, não apresentaram efeitos significativos sobre o perfil lipídico sangüíneo e sobre o desenvolvimento dos animais, mas contribuíram para o aumento no peso do fígado. Já as dietas contendo $10 \%$ e $15 \%$ de FFM foram associadas à redução nos teores plasmáticos de substâncias reativas ao ácido tiobarbitúrico.

Apesar desse efeito positivo, para se recomendar o uso da farinha de folhas de mandioca como antioxidante, mais estudos devem ser realizados para identificar as substâncias causadoras do aumento do peso do fígado. 


\section{AGRADECIMENTOS}

Os autores agradecem ao CNPq e à FAPEMIG pela concessão de bolsas de Mestrado e Iniciação Científica, respectivamente.

\section{REFERÊNCIAS BIBLIOGRÁFICAS}

AKESON, W. R.; STAHMANN, M. A. A pepsin pancreatin digest index of protein quality evaluation. Journal of Nutrition, Bethesda, v. 83, p. 257-261, 1964.

ASSOCIATION OF OFFICIAL ANALYTICAL CHEMISTS. Official methods of analysis of the Association of the Analytical Chemists. 16. ed. Washington, 1995.

BACCOU, J. C.; LAMBERT, F.; SAUVAIRE, Y. Spectrometric method for the determination of total steroidal sapogenin. Analyst, London, v. 102, p. 458-465, 1977.

CAI, Y.; MA, L.; HOU, L.; ZHOU, B.; YANG, L.; LIU, Z. Antioxidant effects of green tea polyphenols on free radical initiated peroxidation of rat liver microssomes. Chemistry and Phisics of Lipids, Lanzhou, v. 120, p. 109-117, 2002.

CARVALHO, V. D. de; PAULA, M. B. de; JUSTE JUNIOR, E. S. G.; KATO, M. de S. A. Características nutritivas de fenos do terço superior e das folhas de cultivares de mandioca. Revista Brasileira de Mandioca, Cruz das Almas, v. 5, n. 1, p. 63-70, 1986.

CORRÊA, A. D. Farinha de folha de mandioca (Manihot esculenta Crantz cv. Baiana): efeito de processamento sobre alguns nutrientes e antinutrientes. 2000. 108 p. Tese (Doutorado em Ciência de Alimentos) - Universidade Federal de Lavras, Lavras, 2000.

CORRÊA, A. D.; SANTOS, C. D. dos; NATIVIDADE, M. A. E.; ABREU, M. C. P. de; XISTO, A. L. R. P.; CARVALHO, V. D. de. Farinha de folhas de mandioca: I. efeito da secagem das folhas sobre a atividade da linamarase. Ciências e Agrotecnologia, Lavras, v. 26, n. 2, p. 368-374, 2002.

CORRÊA, A. D.; SANTOS, S. R. dos; ABREU, C. M. P. de; JOKL, L.; SANTOS, C. D. dos. Remoção de polifenóis da farinha de folhas de mandioca. Ciência e Tecnologia de Alimentos, Campinas, v. 24, n. 2, p. 159-164, 2004.

EUFRÁSIO, M. R. Ação de diferentes tipos de fibras sobre frações lipídicas do sangue e fígado de ratos. 2003. 53 p.
Dissertação (Mestrado em Ciência dos Alimentos) Universidade Federal de Lavras, Lavras, 2003.

FENGLLIN, H.; RUILI, L.; BAO, H.; LIANG, M. Free radical scavehging activity of extracts preparaded from fresh leaves of selected chinese medicinal plants. Fitoterapia, Hefei, v. 75, p. 14-23, 2004.

FONSECA, H. M. T. Composição química de folhas de mandioca (M. esculenta Crantz) tolerantes e suscetíveis ao estresse hídrico. 1996. 90 p. Dissertação (Mestrado em Fisiologia e Bioquímica de Plantas) - Escola Superior de Agricultura de Luiz de Queiroz, Piracicaba, 1996.

GOLDSTEIN, J. L.; SWAIN, T. Changes in tannins in ripening fruits. Phytochemistry, Oxford, v. 2, p. 371-383, 1963.

HEINEMANN, R. B.; COSTA, N. M. B.; CRUZ, R.; PIROZI, M. R. Valor nutricional de farinha de trigo combinada $\mathrm{cm}$ concentrado protéico de folha de mandioca. Revista de Nutrição, Campinas, v. 11, n. 1, p. 51-57, 1998.

INSTITUTO ADOLFO LUTZ. Normas analíticas do Instituto Adolfo Lutz: métodos químicos e físicos para análise de alimentos. 3. ed. São Paulo, 1985. 533 p.

JENKINS, J. K.; ATWAL, A. S. Effects of dietary on fecal bile acids and neutral sterols, and availability of vitamins $A$ and $E$ in the chick. Journal Nutrition Biochemistry, Ottawa, v. 5, p. 134-137, 1994.

MACHADO, D. F.; FERREIRA, C. L. L. F.; COSTA, N. M. B.; OLIVEIRA, T. O. Efeito de probiótico na modulação dos níveis de colesterol sérico e no peso do fígado de ratos alimentados com dieta rica em colesterol e ácido cólico. Ciência e Tecnologia de Alimentos, Campinas, v. 23, n. 2, p.270-275, 2003.

MADRUGA, M. S.; CÂMARA, F. S. The chemical composition of multimistura as a food supplement. Food Chemistry, London, v. 68, p. 41-44, 2000.

MIURA, Y.; CHIBA, T.; MIURA, S.; TOMITA, I.; UMEGAKI, K.; IKEDA, M.; TOMITA, T. Geen tea polyphenols (flavan 3-ols) prevent oxidative modification of low density lipoproteins: an ex vivo study in humans. Journal Biochemistry, Shizuoka, v. 11, p. 216-222, 2000. 
MONTEIRO, C. A. Saúde e nutrição das crianças brasileiras no final da década de 80. In: PERFIL estatístico de crianças e mães no Brasil: aspectos de saúde e nutrição de crianças no Brasil, 1989. Rio de Janeiro: [s.n.], 1992. 129 p.

NWOKOLO, E. Leaf meals of cassava (Manihot esculenta Crantz.) and sian weed (Europatorium odoratum L.) as nutrient sources in poutry diets. Nutrition Reports International, Port Harcourt, v. 36, n. 4, p. 819-826, 1987.

OROZCO, T. J.; WANG, J. F.; KEEN, C. L. Chronic consumption of a flavonol- and procyanidin-rich diet is associated with reduced levels of 8-hydroxy-2deoxyguanosine in rat testes. The Journal of Nutritional Biochemistry, Davis, v. 14, p. 104-110, 2003.

ORTEGA-FLORES, C. I.; COSTA, M. A. L. da; CEREDA, M. P.; PENTEADO, E. M. V. C. Biodisponibilidade do âcaroteno da folha desidratada de mandioca (Manihot esculenta Crantz). Ciência e Tecnologia de Alimentos, Campinas, v. 23, p. 473-477, 2003 a.

ORTEGA-FLORES, C. I.; COSTA, M. A. L. da; CEREDA, M. P.; PENTEADO, M. V. C. Avaliação da qualidade protéica da folha desidratada de mandioca (Manihot esculenta Crantz). Sociedade Brasileira de Alimentos e Nutrição, São Paulo, v. 25, p. 47-59, 2003 b.

PADMAJA, G. Evaluation of techiques to reduce assayable tannin and cyanide in cassava leaves. Journal of Agricultural Food Chemisty, Trivandrum, v. 37, p. 712716, 1989.

RAO, A. V.; KENDALL, C. W. Dietary saponins and serum lipids. Food Chemistry, Toronto, v. 24, n. 5, p. 441, 1986.

RAVINDRAN, G.; RAVINDRAN, V. Changes in the nutritional composition of cassava (Manihot esculenta Crantz) leaves during maturity. Food Chemistry, Oxford, v. 27, p. 299-309, 1988.

REED, J. D.; McDOWELL, R. E.; SOEST, P. J. van; HOWARTH, P. J. Condensed tannins: a factor limiting the use of cassava forrage. Journal Science Food Agriculture, London, v. 33, p. 213-220, 1982.

REEVES, P. G.; NIELSEN, F. H.; FAHEEY, G. C. AIN-93 purified diets for laboratory rodents: final report of the American Institute of Nutrition ad Hoc Writing Committe on the reformulation of the AIN-76 A rodent diet. Journal of Nutrition, Bethesda, v. 123, n. 11, p. 1939-1951, 1993.

ROGERS, D. J.; MILNER, M. Amino acid profile of manioc leaf protein in relation to nutritive value. Economic Botany, New York, v. 17, p. 211-217, 1963.

ROSS, E.; ENRIQUEZ, F. Q. The Nutritive value of cassava leaf meal.Poutry Science, Hawaii, v. 48, n. 3, p. 846-853, 1969.

SILVA, D. J. Análise de alimentos: métodos químicos e biológicos. Viçosa: UFV, 1990. 166 p.

SILVA, M. A. M. Efeito das fibras dos farelos de trigo e aveia sobre o perfil lipídico no sangue e fígado de ratos. 2002. 56 p. Dissertação (Mestrado em Ciência de Alimentos) Universidade Federal de Lavras, Lavras, 2002.

SOUSA, B. A.; SOTO-BLANCO, B.; GUERRA, J. L.; KIMURA, E. T.; GÓRNIAK, S. L. Does prolonged oral exposure to cyanide promote hepatotoxicity and nephrotoxicity? Toxicology, São Paulo, v. 174, p. 87-95, 2002.

VALENCIA, Z.; CHAVEZ, E. R. Lignin as a prurified dietary fiber supplement for piglets. Nutrition Research, Quebec, v. 17, n. 10, p. 1517-1527, 1997.

WITTHAWASKUL, P.; PANTHONG, A.; KANJANAPOTHI, D.; TAESOTHIKUL, T.; LERTPRASERTSUKE, N. Acute and subacute toxicities of saponin mixture isolated from Schefflera leucantha Viguier. Chiang Mai. Journal of Ethnopharmacology, Lausanne, v. 89, p. 115-121, 2003.

WOBETO, C. Nutrientes e antinutrientes da farinha de folhas de mandioca (Manihot esculenta Crantz) em três idades da planta. 2003. 82 p. Dissertação (Mestrado em Agroquímica e Agrobioquímica) - Universidade Federal de Lavras, Lavras, 2003.

WOGAN, G. N.; MARLETTA, M. A. Componentes perjudiciales o potencialmente perjudiciales de los alimentos. In: FENNEMA, O. R. Química de los alimentos. 2. ed. Zaragoza: Acribia, 1993. p. 775-811.

ZDUNCZYK, Z.; FREJNAGEL, M.; WRÓBLEWSKA, M.; JUSKIEWICZ, J.; OSZMIANSKI, J.; ESTRELLA, I. Biological activity of polyphenol extracts from different plant sources. Food Research International, Madrid, v. 35, p. 183-186, 2002. 